\title{
Changes of Laringeal Parameters DURING INTRAuterine Life
}

\author{
A. Gawlikowska-Sroka ${ }^{1}$, D. Miklaszewska1 , E. Dzieciolowska-Baran ${ }^{1}$, E. Kamienska², T. Sroczynski ${ }^{3}$, \\ I. Poziomkowska-Gesicka ${ }^{4}$ \\ ${ }^{1}$ Department of General and Clinical Anatomy, ${ }^{2}$ Clinic of Paediatrics, Haematology and Oncology, \\ ${ }^{3}$ Department of Physiology, and ${ }^{4}$ Department of Clinical Allergology, Pomeranian Medical University, Szczecin, Poland
}

\begin{abstract}
Objective: Increased care of fetal and neonatal airways has led to advances in neonatal medicine. The early diagnosis and treatment of respiratory diseases require a detailed knowledge of fetal airway anatomy and development. The aim of this study was to determine the anatomical development of the thyroid and cricoid cartilages and their structural variability during fetal life. Material and methods: The study was performed on the thyroid and cricoid cartilages of 55 human fetal larynges of both sexes, between the ages of 13 and 27 weeks of intrauterine life. Numerous measurements of the thyroid and cricoid cartilages were performed.

Results: Correlations between the obtained results were calculated in relation to the crown-rump (C-R) length of human fetuses and to sex. The structural variability of the thyroid and cricoid cartilages of human male and female fetuses in subsequent weeks of intrauterine life was observed. In both genders a correlation between laryngeal size and fetal crown-rump length, regardless of sex, was found. The thyroid cartilage presents a sexual dimorphism.

Conclusions: The results of this study can be useful in the analysis of prenatal examinations, and in planning the treatment of airway emergencies.
\end{abstract}

Key words: cricoid cartilage, fetal development, larynx, thyroid cartilage

\section{INTRODUCTION}

Obstruction of the airway and other disorders of the respiratory system have a leading position in the mobility and mortality of newborns, especially in the group of preterm babies. Increased care of fetal and neonatal airways has led to advances in neonatal medicine [1]. The early diagnosis and treatment of respiratory diseases require a detailed knowledge of fetal airway anatomy and development [2].

In the literature, there are many studies concerning the structure of the larynx and its individual cartilages in adults [3-7], but fewer studies concern newborns, infants and children [8-11]. The smallest number of studies concerns the cartilages of the fetal larynx, and the few studies which are available have discrepancies $[2,9,12-14]$. The aim of this study was to determine the anatomical development of the thyroid and cricoid cartilages and their structural variability between the ages of 13 and 27 weeks of intrauterine life. The correlations between fetal crown-rump length, larynx length and the diameters of the examined laryngeal cartilages, as well as gender dimorphism in their structure, were checked.

\section{MATERIAL AND METHODS}

Legal and ethical considerations of the research presented herein were consistent with the rules of our institution and the study was approved by a local Ethics Committee. The material comprised 55 thyroid and cricoid cartilages, isolated from human fetal larynges of both sexes (32 male and 25 female larynges) preserved in $10 \%$ buffered formalin. The fetuses were collected in the Department of General and Clinical Anatomy, Pomeranian Medical University in Szczecin, Poland. The gestational age of fetuses was calculated from crown-rump length (99-255 $\mathrm{mm}$ ) according to Pineau, and was assessed as between 13 and 27 weeks of intrauterine life. The fetuses were free of malformative syndromes affecting the tracheal structures. Measurements were performed with a magnifying glass using a digital calliper accurate to $0.05 \mathrm{~mm}$. To increase the accuracy of measurements, the points between which distances where measured where marked with pins. Each measurement was assessed three times. The following diameters of laryngeal cartilages were measured (Fig. 1I and II): the total laryngeal length (distance between the superior margin of the epiglottis and the inferior margin of the cricoid cartilage), the height of the cricoid cartilage ring (A) and the lamina $(\mathrm{B})$, measured on the midline, the frontal diameter of the inferior margin of the cricoid cartilage (lateral endoluminal diameter) (F), the sagittal diameter of the inferior margin of the cricoid cartilage (anteroposterior endoluminal diameter) $(G)$, the maximal width (C) and height (D) of the right and left laminas of the thyroid cartilage, the median anterior thyroid height (distance between the superior and inferior thyroid incisures) (E), the distance between the base of the superior horns (width of thyroid cartilage) $(\mathrm{H})$. Correlations between the obtained results and fetal C$\mathrm{R}$ length, as well as sexual differences in subsequent weeks of intrauterine life were studied. All data were analyzed statistically using Statistica for Windows software. Measurement error was assessed. Values whose level was $<0.05$ were statistically significant. 
I

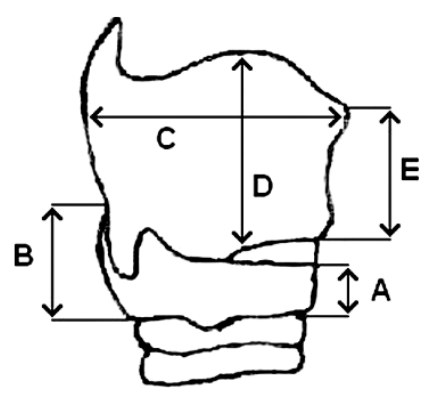

RESULTS

In the studied material we found properly developed thyroid and cricoid cartilages in all fetal larynges. The thyroid cartilage consisted of two symmetrical laminas which were devoid of superior and inferior thyroid tubercles and arcuate line, the angle between both laminae was obtuse and rounded independently of gender (due to technical reasons precise measurements of the angle were not performed), the formed superior and inferior horns of the laminae were observed, and their length correlated with the size of the lamina.

The mean height of the right and left lamina in female fetal larynges was identical, and in male larynges the difference was $0.2 \mathrm{~mm}$ - the right lamina was longer. In one case, we did not find the superior horn in the right lamina (larynx of a male foetus in the $20^{\text {th }}$ week of intrauterine life). Inferior horns were very small and rounded. Superior horns slightly longer than inferior horns took different positions: most often they were slightly curved back, but we also observed
Fig. 1. I - Parameters of cricoid and thyroid cartilages measured in lateral projection: A - cricoid ring height, B - cricoid lamina height, C - thyroid alar width, D - thyroid alar height, and $\mathrm{E}$ - median anterior thyroid height; II - Parameters of cricoid and thyroid cartilages measured in transverse projection: $\mathrm{F}$ lateral endoluminal cricoid diameter, G - anteroposterior endoluminal diameter, and $\mathrm{H}$ - width of thyroid cartilage.

horns curved medially or laterally, or straight horns. The inferior thyroid incisure could not be seen in younger fetal larynges (up to the $20^{\text {th }}$ week of intrauterine life), and in fetuses above the $20^{\text {th }}$ week it was slightly marked. The superior thyroid incisure was clearly apparent in all fetal larynges, but it was shallow and rounded compared to the adult larynx. Table 1 presents the mean diameters of the thyroid cartilage.

The cricoid cartilage consisted of the ring and lamina. In all fetal larynges, regardless of sex, the ring had an elliptical shape and showed a significantly longer diameter in the frontal plane of about $0.6 \mathrm{~mm}$ compared to the sagittal diameter. The lamina had a smooth surface and rounded angles. Table 2 presents the mean diameters of the thyroid cartilage. Results show a strict linear correlation of the size of the examined cartilage elements to total larynx length, which correlates with fetal C-R length (Fig. 2). We observed a significant difference in the width of the thyroid cartilage laminae between male and female fetal larynges. Both laminae, right and left, had a longer transversal diameter in

Table 1. Measurements of the thyroid cartilage (R-right, L-left) in $\mathrm{mm}$.

\begin{tabular}{|c|c|c|c|c|c|c|c|c|}
\hline \multirow{3}{*}{$\begin{array}{c}(\mathrm{HBD}) \\
\text { Fetal } \\
\text { month }\end{array}$} & \multicolumn{2}{|c|}{ Length in midline } & \multicolumn{2}{|c|}{ Length of lamina } & \multicolumn{2}{|c|}{ Width of lamina } & \multicolumn{2}{|c|}{$\begin{array}{l}\text { Distance between } \\
\text { bases of the greater horn }\end{array}$} \\
\hline & \multirow[t]{2}{*}{ Male } & \multirow[t]{2}{*}{ Female } & Male & Female & Male & Female & \multirow[t]{2}{*}{ Male } & \multirow[t]{2}{*}{ Female } \\
\hline & & & $\begin{array}{ll}\mathrm{R} & \mathrm{L}\end{array}$ & $\begin{array}{ll}\mathrm{R} & \mathrm{L}\end{array}$ & $\begin{array}{ll}\mathrm{R} & \mathrm{L}\end{array}$ & $\begin{array}{ll}\mathrm{R} & \mathrm{L} \\
\end{array}$ & & \\
\hline 13 & 4.7 & 4.8 & $5.8 \quad 5.7$ & 5.55 .6 & 3.13 .1 & $2.9 \quad 2.8$ & 6.3 & 6.4 \\
\hline 14 & 4.7 & 4.9 & $5.8 \quad 5.7$ & 5.55 .7 & 3.13 .1 & 2.92 .9 & 6.4 & 6.5 \\
\hline 15 & 4.8 & 4.9 & 6.06 .1 & 5.95 .9 & 3.23 .2 & 3.03 .0 & 6.5 & 6.5 \\
\hline 16 & 4.9 & 4.8 & $6.0 \quad 6.2$ & 6.06 .0 & 3.33 .4 & 3.13 .1 & 6.6 & 6.7 \\
\hline 17 & 4.9 & 5.0 & 6.16 .2 & 6.16 .0 & 3.43 .4 & 3.23 .2 & 6.7 & 6.8 \\
\hline 18 & 5.0 & 5.0 & 6.76 .7 & 6.26 .4 & 3.43 .4 & 3.23 .2 & 6.8 & 6.8 \\
\hline 19 & 5.3 & 5.4 & 6.86 .8 & 6.56 .6 & 3.53 .5 & $3.3 \quad 3.3$ & 6.9 & 6.9 \\
\hline 20 & 5.4 & 5.4 & 7.07 .1 & 7.07 .0 & 3.73 .7 & 3.53 .5 & 7.1 & 7.0 \\
\hline 21 & 5.4 & 5.6 & 7.17 .2 & 7.07 .1 & 3.73 .7 & 3.53 .5 & 7.3 & 7.4 \\
\hline 22 & 5.6 & 5.6 & 7.37 .4 & 7.37 .3 & 3.83 .8 & $3.5 \quad 3.5$ & 7.6 & 7.5 \\
\hline 23 & 5.7 & 5.7 & 7.27 .3 & 7.17 .1 & 3.73 .7 & $3.5 \quad 3.5$ & 7.6 & 7.5 \\
\hline 24 & 5.8 & 5.8 & 7.37 .4 & 7.37 .3 & 4.14 .1 & 3.53 .5 & 7.8 & 7.5 \\
\hline 25 & 5.8 & 5.9 & 7.37 .4 & 7.37 .3 & 4.24 .3 & $3.5 \quad 3.5$ & 7.8 & 7.6 \\
\hline 26 & 5.9 & 6.0 & 7.47 .4 & 7.37 .3 & $4.4 \quad 4.4$ & $3.5 \quad 3.5$ & 7.9 & 7.9 \\
\hline 27 & 6.0 & 6.0 & 7.57 .6 & 7.47 .4 & 4.54 .5 & $3.6 \quad 3.6$ & 8.0 & 7.7 \\
\hline
\end{tabular}


Table 2. Measurements of the cricoid cartilage.

\begin{tabular}{|c|c|c|c|c|c|c|c|c|}
\hline \multirow[t]{2}{*}{$\begin{array}{c}\text { Age } \\
\text { (weeks) }\end{array}$} & \multicolumn{2}{|c|}{$\begin{array}{l}\text { Height of ring } \\
\text { of cricoid cartilage }\end{array}$} & \multicolumn{2}{|c|}{$\begin{array}{l}\text { Height of lamina } \\
\text { of cricoid cartilage }\end{array}$} & \multicolumn{2}{|c|}{$\begin{array}{l}\text { Frontal diameter } \\
\text { of interior margin } \\
\text { of cricoid cartilage }\end{array}$} & \multicolumn{2}{|c|}{$\begin{array}{l}\text { Sagittal diameter } \\
\text { of interior margin } \\
\text { of cricoid cartilage }\end{array}$} \\
\hline & Male & Female & Male & Female & Male & Female & Male & Female \\
\hline 13 & 1.9 & 2.0 & 2.9 & 3.0 & 4.3 & 4.4 & 3.8 & 3.6 \\
\hline 14 & 2.0 & 2.1 & 3.0 & 3.1 & 4.4 & 4.5 & 3.8 & 3.7 \\
\hline 15 & 2.1 & 2.3 & 3.1 & 3.3 & 4.5 & 4.5 & 3.8 & 3.8 \\
\hline 16 & 2.3 & 2.3 & 3.3 & 3.4 & 4.7 & 4.7 & 4.0 & 3.9 \\
\hline 17 & 2.5 & 2.6 & 3.5 & 3.6 & 4.7 & 4.9 & 4.0 & 3.9 \\
\hline 18 & 2.7 & 2.7 & 3.6 & 3.7 & 4.9 & 4.8 & 4.0 & 4.0 \\
\hline 19 & 2.8 & 2.9 & 3.8 & 3.9 & 5.0 & 5.0 & 4.8 & 4.7 \\
\hline 20 & 2.9 & 3.0 & 3.9 & 4.0 & 5.3 & 5.1 & 4.9 & 4.8 \\
\hline 21 & 3.4 & 3.5 & 4.4 & 4.5 & 5.8 & 5.9 & 5.4 & 5.1 \\
\hline 22 & 3.9 & 3.6 & 4.9 & 4.6 & 6.1 & 6.1 & 5.9 & 5.2 \\
\hline 23 & 3.9 & 3.8 & 4.9 & 4.9 & 6.2 & 6.2 & 5.9 & 5.5 \\
\hline 24 & 4.1 & 4.2 & 5.1 & 4.8 & 6.6 & 6.2 & 6.1 & 6.1 \\
\hline 25 & 4.2 & 4.1 & 5.2 & 5.1 & 6.7 & 6.3 & 6.0 & 6.1 \\
\hline 26 & 4.2 & 4.2 & 5.3 & 5.2 & 6.8 & 6.4 & 6.1 & 6.1 \\
\hline 27 & 4.3 & 4.3 & 5.3 & 5.2 & 6.9 & 6.4 & 6.2 & 6.2 \\
\hline
\end{tabular}

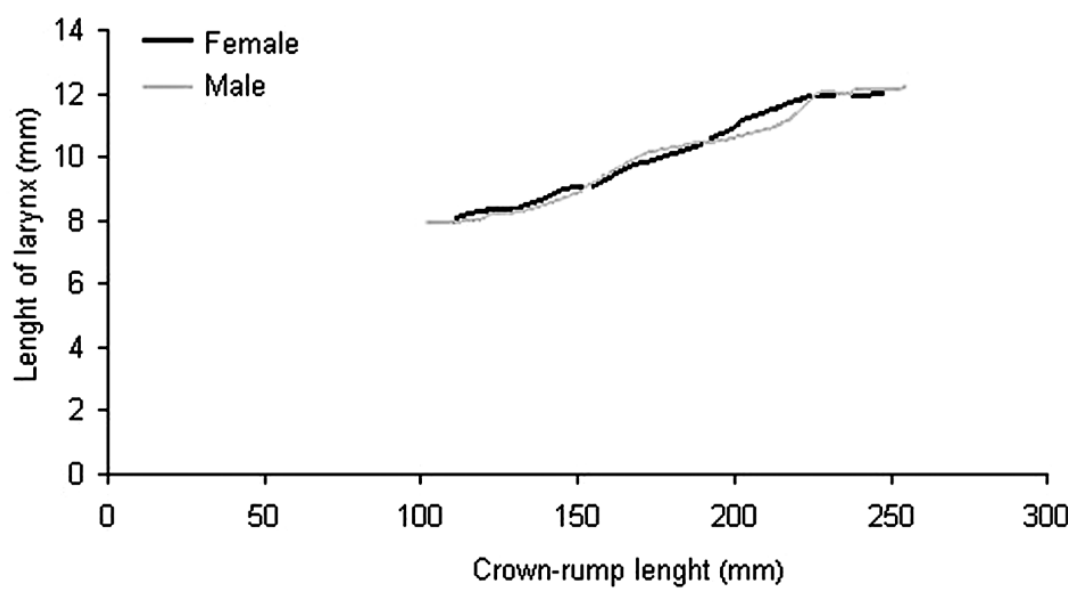

Fig. 2. Relationship between the length of larynx and that of crown-rump. males, regardless of age and crown-rump length. The difference was $0.4 \mathrm{~mm}$ on average. There was no significant difference in the length of the examined cartilage.

The thyroid foramen was observed in 30 thyroid cartilages, in 4 cases bilaterally and in the rest unilaterally. The presence or absence of the foramen in the thyroid cartilage did not show any relationship to fetal sex.

\section{DiscusSION}

Nowadays, many leading children's hospitals are creating fetal care centers which are based on the pediatrics model of fetal care, in contrast to the obstetrics-based model that offers traditional care to pregnant women and fetuses [15]. This provides better perinatal health care.
Development of the fetus' respiratory tract during pregnancy can be disturbed by many factors: smoking by the mother, intrauterine infections, genetic disorders and others. Early treatment of anatomical or functional respiratory abnormalities in early childhood or during intrauterine life prevents the occurrence of respiratory disorders later in life [1]. Technological advances in prenatal radiological examinations (USG, NMR) have improved the ability to diagnose congenital abnormalities during pregnancy. Some studies suggest that many airway emergencies can be avoided by prenatal initiation of airway management [16]. In cases of suspected severe airway obstruction, elective full caesarean delivery is suggested [17]. This significantly decreases maternal complications and allows for better airway access in the newborn. Utero-placental circulation and gas exchange maintains vital functions and provides time to perform procedures (laryngoscopy, 
tracheostomy, etc.) to secure the fetal airway [18, 19]. Detailed information about development (size, gender differences, etc) is needed for a correct assessment of diagnostic examinations and for the planning of otolaryngology or surgical treatment. Our research was in answer to this necessity.

We know that the thyroid and cricoid cartilages are among the biggest azygous laryngeal cartilages, and are fundamental elements of the chondroskeleton of the larynx, so they were closely examined in our study. They also play an important sustentacular role for soft tissues in the larynx and a protective role for the vocal apparatus and laryngeal segment of the respiratory system $[4,20,21]$. With sexual maturity, the structural variability of these cartilages influences features associated with gender, such as timber or the presence of laryngeal prominence $[20,22]$.

There are many reports in the literature about the larynx, its development, structure, sexual dimorphism and pathology $[14,23-26]$. Few authors study individual laryngeal cartilages [3, 6, 9, 13, 20, 22, 27], and when they do, their studies often concern the process of cartilage ossification in adults $[4,6,25]$. Fetal laryngeal cartilages were studied by Fayoux et al [2] and Jelisiejew and Szmurlo [4]. We agree with previous authors that fetal laryngeal cartilages are not a miniaturization of the cartilages of the adult [9] and also that their size correlates with larynx size which, in turn, exhibits a linear relationship with fetal C-R length $[9,12$, 13]. However, there are different opinions concerning sexual dimorphism during intrauterine life. Jelisiejew and Szumilo [4], Lang et al [25], and Kahane [12] claim that before puberty there are no sexual differences in the structure of the larynx, whereas Winiarski et al [28] find sexual differences already in the fetal period. These differences are reflected in the bigger diameters of some laryngeal elements. Winiarski et al [28] state that sexual dimorphism appears in the fetal period, but this is not strongly expressed and concerns only a few laryngeal diameters and a few periods in intrauterine life - it is present in the $5^{\text {th }}$ and $6^{\text {th }}$ month of intrauterine life, but disappears between the $7^{\text {th }}$ month and birth. These differences are probably the result of techniques of examination which were not homogeneous, and different materials and methods of fixation and storage. There is no unequivocal evidence for the presence of gender differences in the structure of individual laryngeal cartilages [9]. Fayoux et al [2] were the first to report of sexual dimorphism regarding the thyroid cartilage. Our previous studies showed a linear relationship between laryngeal cartilage size and fetal length and their regular growth regardless of sex [20]. In the present study we observed a significantly bigger width of both thyroid cartilage laminae in males in all age groups. This confirmed the existence of sexual dimorphism in the structure of the fetal larynx. If we consider the fact that the width of the laminae and their inclination to the front produces the laryngeal prominence which is an unequivocal sexual feature in the adult male, we can then suggest that some features of sexual dimorphism are already present between the $13^{\text {th }}$ and $27^{\text {th }}$ week of the fetal period.

In conclusion, in both genders the thyroid and cricoid laryngeal cartilages show regular symmetrical growth proportional to individual growth. The size of the laryngeal cartilages is directly proportional to fetal crown-rump length, regardless of sex. The thyroid cartilage presents a sexual dimorphism. The results of this study can be used in the analysis of prenatal examinations and in planning the treatment of airway emergencies.

Conflicts of interest: No conflicts of interests were declared by the authors in relation to this article.

\section{REFERENCES}

1. Nosal S, Durdik P, Sutovska M, Franova S, Nosal V, Koppl J, Hamzik J, Banovcin P. Changes of airway obstruction parameters in healthy children caused by the mother's smoking during pregnancy. J Physiol Pharm 2008; 59 Suppl 6: 523-9.

2. Fayoux P, Marciniak B, Devisme L, Storme L. Prenatal and early postnatal morphogenesis and growth of human laryngotracheal structures. J Anat 2008; 213: 86-92.

3. Jani J, Gratacos E, Greenough A, Piero JL, Benachi A, Harrison M, Nicolaides K, Deprest J. Percutaneous fetal endoscopic tracheal occlusion (FETO) for severe leftsided congenital diaphragmatic hernia. Clin Obstet Gynecol 2005; 48: 910-22.

4. Jelisiejew T, Szmurlo J. Structural varieties of the thyroid cartilage. Folia Morphol 1972; 31: 127-32.

5. Kalache KD, Nishima H, Ojutiku D, Hanson MA. Visualisation and measurement of tracheal diameter in the sheep fetus: an ultrasound study with stereomicroscopic correlation. Fetal Diagn Ther 2001; 16: 342-5.

6. Kohl T, Hering R Bauriedel G, Van de Vondel P, Heep A, Keiner S, Müller A, Franz A, Bartmann P, Gembruch U. Fetoscopic and ultrasound-guided decompression of the fetal trachea in a human fetus with Fraser's syndrome and congenital high airway obstruction syndrome (CHAOS) from laryngeal atresia. Ultrasound Obstet Gynecol 2006; 27: 84-8.

7. Sanudo JR, Domenech-Mateu JM. The laryngeal primordium and epithelial lamina. A new interpretation. J Anat 1990; 171: 207-22.

8. Eckel HE, Sprinzl GM, Sittel C. Zur Anatomie von Glottis und Subglottis beim kindlichen Kehlkopf. HNO 2000; 48: 501-7.

9. Fayoux P, Devisme L, Merrot O, Chevalier D, Gosselin B. Histologic structure and development of the laryngeal macula flava. Ann Otol Rhinol Laryngol 2004; 113: 498504.

10. Muller F, O’Rahilly R, Tucker J. The human larynx at the end of the embryonic period proper. Acta Otolaryngol 1981; 91: 323-36.

11. Maranillo E, Vazquez T, Mirapeix R, Leon X, McHanwell S, Quer M, Sanudo JR. Ceratocricoid muscle: an embryological and anatomical study. Clin Anat 2009; 22: 463-70.

12. Kahane JC. A morphological study of the human prepubertal and pubertal larynx. Am J Anat 1978; 151: 11-20.

13. Kalache KD, Franz M, Chaoui R, Bollmann R. Ultrasound measurements of the diameter of the fetal trachea, larynx and pharynx throughout gestation applicability to prenatal diagnosis of obstructive anomalies of the upper respiratory-digestive tract. Prenat Diagn 1999; 19: 211-8.

14. Vazquez T, Cobiella R, Maranillo E, Valderrama FJ, McHanwell S, Parkin I, Sanudo JR. Anatomical variations of the superior thyroid and superior laryngeal arteries. Head Neck 2009; 31: 1078-85.

15. Brown SD, Lyerly AD, Little MO, Lantos JD. Paediatricsbased fetal care: unanswered ethical questions. Acta Paediatr 2008; 97: 1617-1619. 
16. Rahbar R, Vogel A, Myers LB, Bulich LA, Wilkins-Haug L, Benson CB, Grable IA, Levine D, Fishman SJ, Jennings RW, Estroff JA, Barnewolt CE. Fetal surgery in otolaryngology: a new era in the diagnosis and management of fetal airway obstruction because of advances in prenatal imaging. Arch Otolaryngol Head Neck Surg 2005; 131: 393 8.

17. Preciado DA, Ruter MJ, Greenberg JM, Bahado-Singh R, Lambers D, Willing JP. Intrapartum management of severe fetal airway obstruction. J Otolaryngol 2004; 33: 283-8.

18. Howell LJ, Burns KM, Lenghetti E, Kerr JC, Harkins LS. Management of fetal airway obstruction: an innovative strategy. MCN Am J Matern Child Nurs 2002; 27: 238-43.

19. Liechty KW, Crombleholme TM. Management of fetal airway obstruction. Semin Perinatol 1999; 23: 496-506.

20. Adamiec E, Dzieciolowska-Baran E, Czerwinski F, Miklaszewska D, Teul I. Prenatal development of the human trachea. Folia Morphol 2002; 61:123-5.

21. Lisser H. Studies on the development of the human larynx. J Anat 1911; 12: 27-66.

22. Brzezinska H, Krawczynski M, Makowski A. Anatomy of the larynx in newborn infants and infants. Selected problems (preliminary communication). Otolaryngol Pol 1976; 30: 451-6 (Article in Polish).

23. Harrison MR, Keller RL, Hawgood SB, Kitterman JA, Sandberg PL, Farmer DL, Lee H, Filly RA, Farrell JA, Albanese CT. A randomized trial of fetal endoscopic tracheal occlusion for severe fetal congenital diaphragmatic hernia. N Engl I Med 2003; 349: 1916-24.
24. Kirchner JC, Kirchner JA, Sasaki CT. Anatomic foramina in the thyroid cartilage: Incidence and implications for the spread of laryngeal cancer. Otol Rhinol Laryngol 1989; 98: 421-5.

25. Lang J, Fisher K, Nachbaur S. On the measurements, shape and form varieties of the thyroid and cricoid cartilages. Gegenbaurs Morph Jb 1984; 130: 639-57.

26. Vorperian HK, Wang S, Chung MK, Schimek EM, Durtschi RB, Kent RD, Ziegert AJ. Gentry LR Anatomic development of the oral and pharyngeal portions of the vocal tract: an imaging study. J Acoust Soc Am 2009; 125: 1666-78.

27. Strek P, Nowogrodzka-Zagorska M, Miodonski AJ, Olszewski E. Microvasculatur of the human fetal laryngeal anterior commissure. Fol Morphol 1997; 56: 223-8.

28. Winiarski P, Bozilow W, Betlejewski S, Krakowiak J. The biometric investigation of the thyroid cartilage in human prenatal development. Otolaryngol Pol 1994; 48: 360-6.

Address for correspondence:

Aleksandra Gawlikowska-Sroka

Department of General and Clinical Anatomy

Pomeranian Medical University

72, Powstancow Wlkp. St.

70-111 Szczecin

Poland

Phone: +48914661480

Fax: $\quad+48914661481$

E-mail: gawlikow@ams.edu.pl 